\title{
Article \\ The Biocatalytic Production of 3-Hydroxypropionaldehyde and Evaluation of Its Stability
}

\author{
Jung-Hyun Ju ${ }^{1}$, Sang-Gyu Jeon ${ }^{1}$, Kyung Min Lee ${ }^{2}$, Sun-Yeon Heo ${ }^{1}$, Min-Soo Kim ${ }^{1}$, Chul-Ho Kim ${ }^{1}$ \\ and Baek-Rock Oh ${ }^{1, *}$ \\ 1 Microbial Biotechnology Research Center, Jeonbuk Branch Institute, Korea Research Institute of Bioscience \\ and Biotechnology (KRIBB), Jeongeup 56212, Korea; joojh@kribb.re.kr (J.-H.J.); zom0@kribb.re.kr (S.-G.J.); \\ heosy@kribb.re.kr (S.-Y.H.); ms5732@kribb.re.kr (M.-S.K.); kim3641@kribb.re.kr (C.-H.K.) \\ 2 Kolon Advanced Research Cluster, Kolon Industries, Gangseo, Seoul 07793, Korea; \\ kyungmin_lee1@kolon.com \\ * Correspondence: baekrock.oh@kribb.re.kr
}

check for updates

Citation: Ju, J.-H.; Jeon, S.-G.; Lee, K.M.; Heo, S.-Y.; Kim, M.-S.; Kim, C.-H.; Oh, B.-R. The

Biocatalytic Production of 3Hydroxypropionaldehyde and Evaluation of Its Stability. Catalysts 2021, 11, 1139. https://doi.org/ $10.3390 /$ catal11101139

Academic Editors: Baiyu Zhang, Bo Liu and Takeshi Sugai

Received: 28 July 2021

Accepted: 17 September 2021

Published: 23 September 2021

Publisher's Note: MDPI stays neutral with regard to jurisdictional claims in published maps and institutional affiliations.

Copyright: (C) 2021 by the authors Licensee MDPI, Basel, Switzerland. This article is an open access article distributed under the terms and conditions of the Creative Commons Attribution (CC BY) license (https:// creativecommons.org/licenses/by/ $4.0 /)$

\begin{abstract}
Hydroxypropionaldehyde (3-HPA, reuterin) is a broad-spectrum natural antimicrobial agent used in the food industry and other fields. The low yield from the industrial production of 3-HPA using Lactobacillus reuteri and the spontaneous conversion of 3-HPA to acrolein have limited its more widespread use. We isolated L. reuteri BR201 as a biocatalyst for 3-HPA production and confirmed the effect of each factor in the two-step procedure for 3-HPA bioconversion. After initial cultivation for $8 \mathrm{~h}$ (late exponential phase), this isolate produced $378 \mathrm{mM}$ of 3 -HPA in $1 \mathrm{~h}$ at a concentration of $\mathrm{OD}_{600 \mathrm{~nm}} 100,30{ }^{\circ} \mathrm{C}$, and an initial glycerol concentration of $500 \mathrm{mM}$. This is the highest reported biocatalytic yield of 3-HPA from a glycerol aqueous solution without additives. We confirmed that $4 \mathrm{mM}$ of 3-HPA had antimicrobial activity against five pathogens. The degradation of 3-HPA to acrolein was greater at high temperatures, and there was little degradation when 3-HPA was maintained at $4{ }^{\circ} \mathrm{C}$ for 4 weeks. Our results may be useful for future applications of 3-HPA.
\end{abstract}

Keywords: Lactobacillus reuteri; 3-hydroxypropionaldehyde; reuterin; antibiotic; stability evaluation

\section{Introduction}

3-Hydroxypropionaldehyde (3-HPA, reuterin), which has hydroxy and aldehyde functional groups, has many industrial uses and can be used as a platform for the synthesis of acrolein, 3-hydroxypropionic acid (3-HP), 1,3-propanediol (1,3-PDO), malonic acid, acrylamide, and acrylic acid [1-3]. The food industry [4,5] and healthcare industry [1] use 3-HPA as an antimicrobial agent. In 1960, Sobolov and Smiley first reported that 3-HPA was a metabolite of glycerol that was produced in lactobacilli [6]. The name 'reuterin' is derived from Lactobacillus reuteri [7], the heterologous fermentative lactic acid bacteria (LAB) that produce this compound. There is a report that reuterin occurs as an equilibrium mixture of monomeric, hydrated monomeric, and cyclic dimeric forms of 3-HPA [8].

L. reuteri is utilized in a variety of fermented foods, such as sourdough, meat, and dairy products [1,9], and is also a natural inhabitant of gastrointestinal and urogenital tracts of humans and other animals [2,10]. In 2008, the US Food and Drug Administration (FDA) granted L. reuteri the status of 'generally regarded as safe' (GRAS) [11]. 3-HPA is an intermediate in the conversion of glycerol to 1,3-PDO in L. reuteri. This pathway is important because it regenerates NAD+ from the NADH that is produced by glucose metabolism and contributes to improved growth [12]. L. reuteri can naturally convert glycerol to 3-HPA, but it cannot directly use 3-HPA as a carbon source for growth [13]. Therefore, the bioconversion of 3-HPA by L. reuteri may be considered a two-step process: (i) proliferation of cells during cultivation and (ii) conversion of glycerol into 3-HPA by resting cells. There are several available methods of 3-HPA bioconversion, but they have disadvantages of low titers and conversion rates $[3,7,14]$ or the need for additional refining 
processes $[15,16]$. The advantage of using a two-step process with L. reuteri is that the final purification procedure is very simple.

3-HPA can undergo spontaneous dehydration to acrolein in aqueous solutions [17], and acrolein is now included in the definition of reuterin [17,18]. Acrolein consumption is widespread because it is generated from overheated vegetable and animal fats that occur in cooked, fried, and charred foods, and is also present in beer, wine, rum, and breads. However, acrolein has long been considered a harmful substance, and WHO working group suggested the "tolerable oral acrolein intake" should be limited to $7.5 \mu \mathrm{g}$ per day per $\mathrm{kg}$ body weight [19]. Thus, the spontaneous conversion of 3-HPA to acrolein is an obstacle that prevents the more widespread use of 3-HPA in different applications.

The purpose of the present study was to develop a method for the efficient bioconversion of glycerol to 3-HPA by L. reuteri, and to evaluate its chemical stability. Thus, L. reuteri BR201 (isolated from infant feces) used to study a two-step bioconversion process, by first determining the cell stage when 3-HPA bioconversion occurred, and then confirming the effect of bioconversion conditions (cell density, temperature, glycerol concentration, conversion time) for 3-HPA production. We also measured the antimicrobial activity of the resulting 3-HPA, and the effect of temperature on the degradation of 3-HPA to acrolein in aqueous solution over 4 weeks.

\section{Results and Discussion}

\subsection{Isolation and Identification L. reuteri BR201}

L. reuteri is known to produce 3-HPA, but there are differences among strains [7]. Thus, we attempted to isolate a new strain of this species that more efficiently produced 3-HPA from glycerol. We identified several potential LAB isolates from infant feces based on color, using MRS agar containing $20 \mathrm{~g} / \mathrm{L}$ glycerol and $0.3 \mathrm{~g} / \mathrm{L}$ bromocresol purple. We analyzed these isolates using the matrix-assisted laser desorption ionization (MALDI) Biotyper system (Bruker Daltonik, Bremen, Germany), and tested them for growth and glycerol utilization in MRS medium containing $20 \mathrm{~g} / \mathrm{L}$ glycerol at anaerobic conditions. L. reuteri BR201 grew faster than all the other isolates and produced more 3-HPA. The identity of this isolate was confirmed using $16 \mathrm{~S}$ rRNA analysis. The NCBI BLAST results showed high similarity ( $>99 \%$ ) to $L$. reuteri JCM $1112 \mathrm{~T}$ (AP007281). The $16 \mathrm{~S}$ rRNA sequence of L. reuteri BR201 into the NCBI nucleotide sequence database (accession No. MZ269211) and $L$. reuteri BR201 strain also deposited it at the Korea Collection for Type Cultures (accession No. KCTC 14343BP). Figure 1 shows the relationship with other Lactobacillus strains using the neighbor-joining method. The results shown that L. reuteri BR201 was closest to L. reuteri JCM 1112T (bootstrap value: $100 \%$ ), and the phylogenetic tree indicated that $L$. reuteri BR201 was included in a monophyletic group containing other Lactobacillus sp. strains.

\subsection{The Effect of Cell Growth for 3-HPA Bioconversion}

We used a two-step procedure to produce 3-HPA using L. reuteri. The first step was promotion of cell growth using batch culture, and the second step was conversion of glycerol into 3-HPA using resting cells as biocatalytic.

Thus, we first grew cells by batch cultivation in MRS medium containing $20 \mathrm{~g} / \mathrm{L}$ glycerol and $18 \mathrm{~g} / \mathrm{L}$ glucose to activate genes that function in glycerol metabolism [3]. These results indicated that cells consumed all of the carbon source after $8 \mathrm{~h}$, and the cell growth at this time reached $\mathrm{OD}_{600 \mathrm{~nm}} 8.8$ (Figure 2). The bioconversion glycerol to 3-HPA had a similar tendency, in that it increased during the exponential phase $(6 \mathrm{~h}, 324.1 \mathrm{mM})$ and the late exponential phase $(8 \mathrm{~h}, 325.6 \mathrm{mM})$. However, because cell proliferation during the late exponential phase was about 1.62-fold greater than during the exponential phase, it was possible to produce a 1.62-fold more 3-HPA using the same amount of cultivation broth. Cells were in the stationary phase at $10 \mathrm{~h}$, and the bioconversion of 3-HPA was 20\% $(w / w)$ lower at that time. As shown in Table 1, the same amount of cells were present at the late exponential phase $(8 \mathrm{~h})$ and the stationary phase $(10 \mathrm{~h})$, but less glycerol was consumed 
at the stationary phase. This appears to be due to a decrease in cell activity from $8 \mathrm{~h}$ to $10 \mathrm{~h}$. Similarly, Lüthi-Peng et al. reported that the L. reuteri ATCC 53608 strain produced the most 3-HPA during the late exponential/early stationary phase [3]. They also found that as cell age increased, the amount of viable cells and cell activity decreased [3]. Because cells most effectively produced 3-HPA during the late exponential phase, our subsequent experiments used cells harvested at this time.

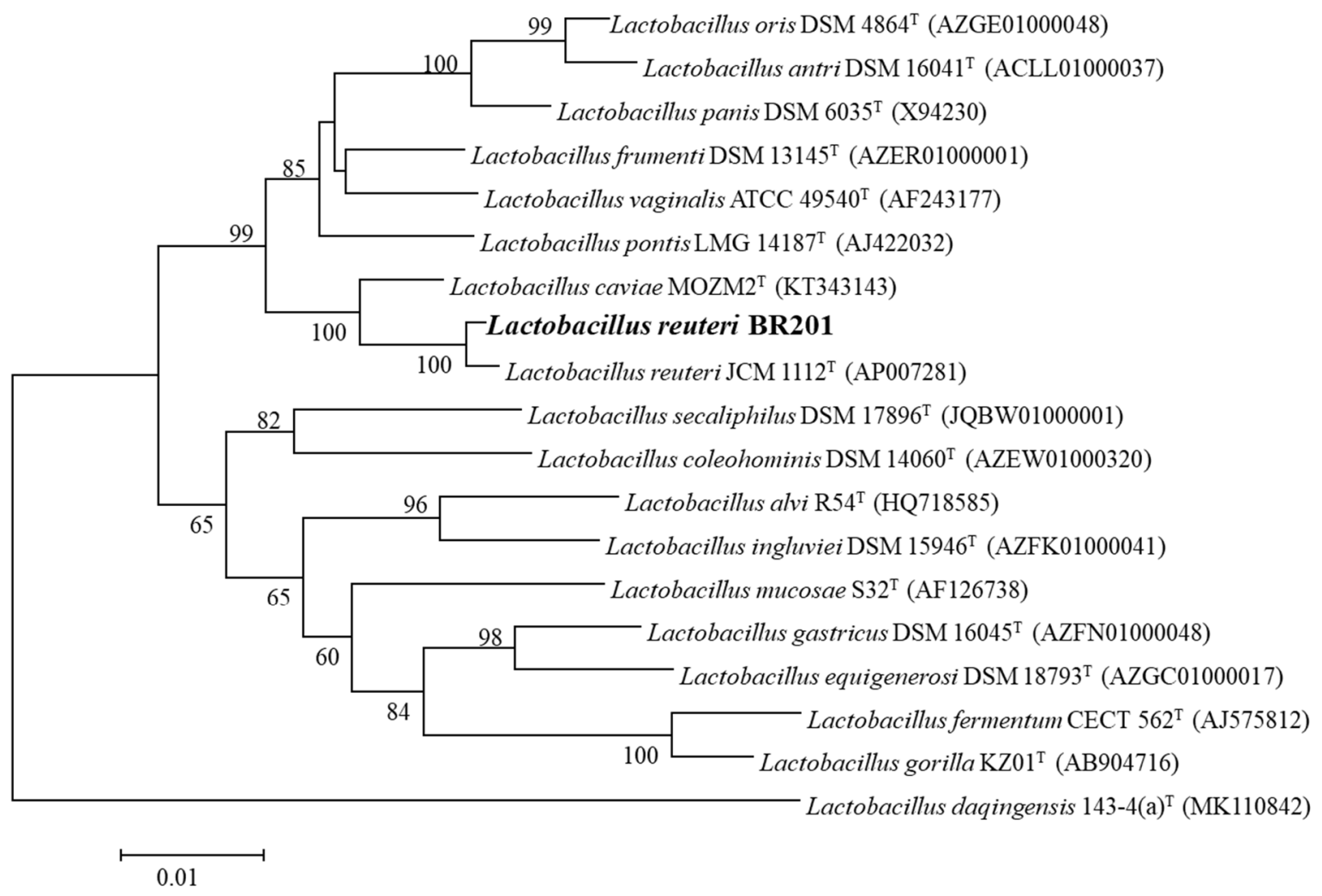

Figure 1. The neighbor-joining phylogenetic tree of Lactobacillus reuteri BR201 based on 16S rRNA gene sequences. The number at each branch represents the bootstrap value (\%) for the node calculated from 1000 replicates. Bar: 0.01 substitutions per nucleotide.

Table 1. The Effect of cultivation time on the levels of residual glycerol, 3-hydroxypropionaldehyde, and 1,3-propanediol by L. reuteri BR201.

\begin{tabular}{cccc}
\hline Cultivation Time (h) & $\begin{array}{c}\text { Regidual Glycerol } \\
\text { (mM) }\end{array}$ & 3-HPA (mM) & 1,3-PDO (mM) \\
\hline 4 & $137.5 \pm 2.1$ & $214.2 \pm 2.6$ & $37.8 \pm 0.2$ \\
6 & $14.1 \pm 0.1$ & $324.1 \pm 3.8$ & $59.9 \pm 0.6$ \\
8 & $11.4 \pm 0.1$ & $325.6 \pm 4.3$ & $61.8 \pm 0.5$ \\
10 & $195.9 \pm 1.2$ & $168.5 \pm 2.7$ & $34.2 \pm 0.4$ \\
\hline
\end{tabular}




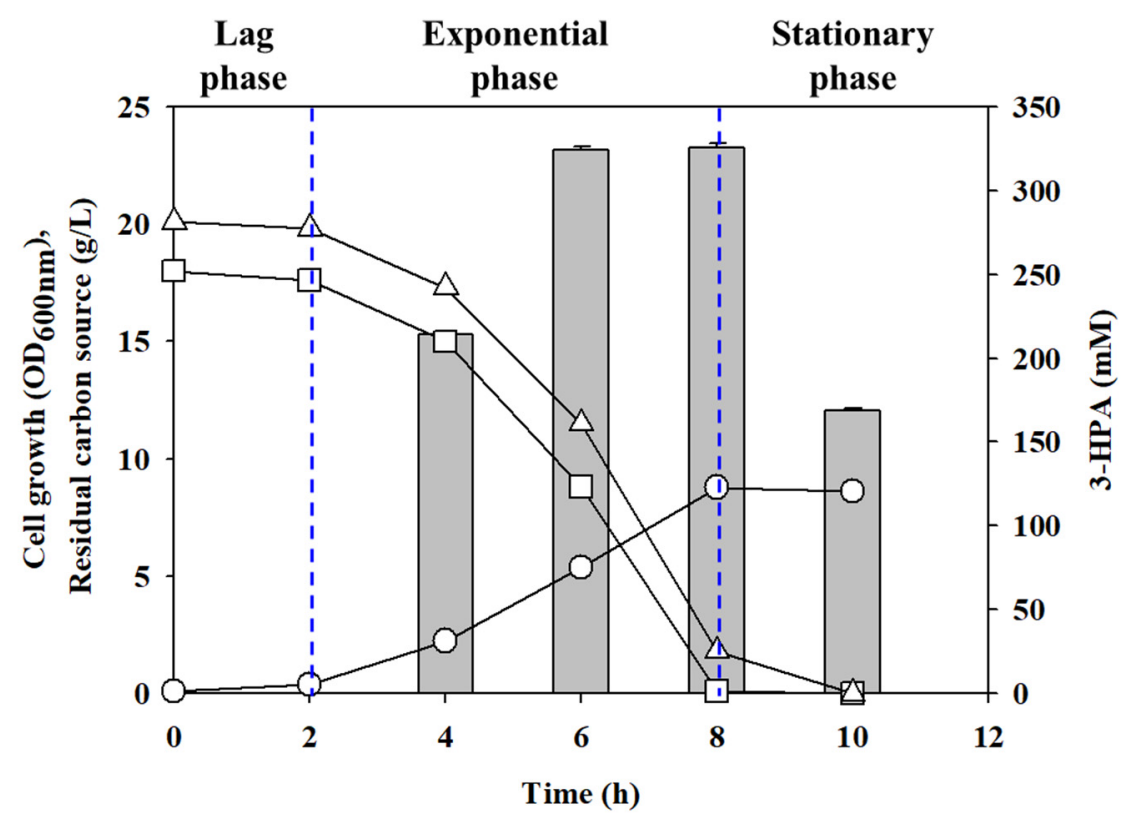

Figure 2. Batch cultivation of Lactobacillus reuteri BR201 and bioconversion of 3hydroxypropionaldehyde during different growth phases. Open triangles, residual glycerol; open squares, residual glucose; open circles, cell growth; gray bars, 3-hydroxypropionaldehyde concentration. All results are averages from three independent experiments.

\subsection{The Effect of Cell Density}

We first examined the effect of different cell density on the production of 3-HPA under basic bioconversion conditions (Figure 3a). The results indicated that 3-HPA bioconversion occurred at all tested cell density $\left(\mathrm{OD}_{600 \mathrm{~nm}} 20 \sim 200\right)$ under the basic bioconversion conditions. The bioconversion of 3-HPA was the highest $(325.1 \mathrm{mM})$ when the cell density was $\mathrm{OD}_{600 \mathrm{~nm}}$ 100. As cell density increased above this level, the production of 1,3-PDO increased and there was no change in the amount of residual glycerol. In agreement, Lüthi-Peng et al. also reported that 3-HPA production decreased when the cell density increased above certain level [3]. L. reuteri metabolizes glycerol into 3-HPA and 1,3-PDO using vitamin $\mathrm{B}_{12}$-dependent glycerol dehydratase $(\mathrm{dha} B$ ) and 1,3-propanediol oxidoreductase (dhaT) [20]. In the case of $d h a T, \mathrm{NADH}$ is used as a coenzyme. The NADH generated during the cell growth step of LAB is used as a coenzyme to convert 3-HPA to 1,3-PDO by dhaT during 3-HPA bioconversion. Therefore, a higher cell density leads to greater total $\mathrm{NADH}$ and an increased level of 1,3-PDO. Our results demonstrated that when the cell density was high, the amount of 3-HPA decreased because the bioconversion of 1,3-PDO increased. We therefore used a cell density of $\mathrm{OD}_{600 \mathrm{~nm}} 100$ for subsequent experiments.

\subsection{The Effect of Temperature}

We next examined the effect of different temperatures on the bioconversion of 3-HPA (Figure $3 \mathrm{~b}$ ). The results indicated a temperature of $30^{\circ} \mathrm{C}$ led to the greatest bioconversion of 3-HPA $(338.3 \mathrm{mM})$. On the other hand, the production of 1,3-PDO was the highest $(64.2 \mathrm{mM})$ at $37^{\circ} \mathrm{C}$. Similarly, Doleyres et al., studied the L. reuteri ATCC 53608 strain and reported that the optimal temperature for 3-HPA production was $30^{\circ} \mathrm{C}$ [14]. 
a

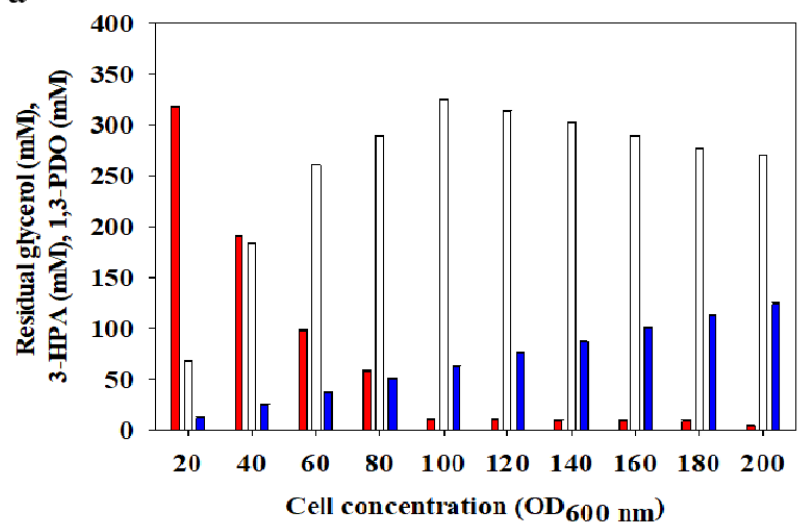

c

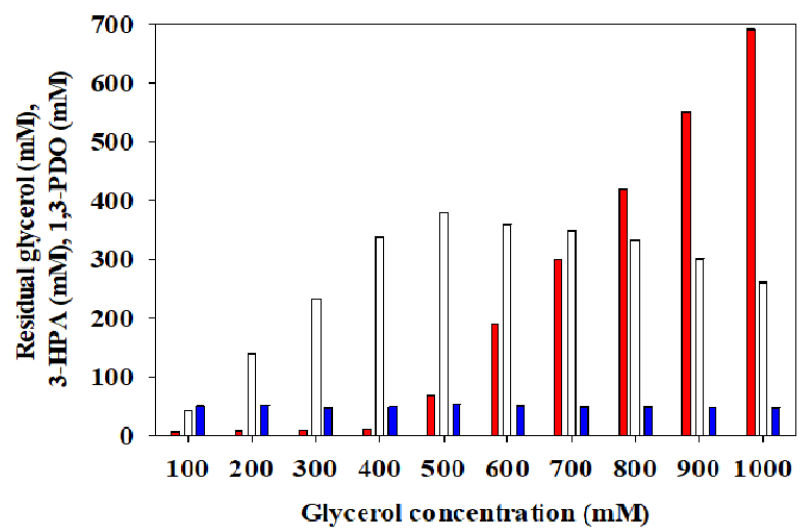

b

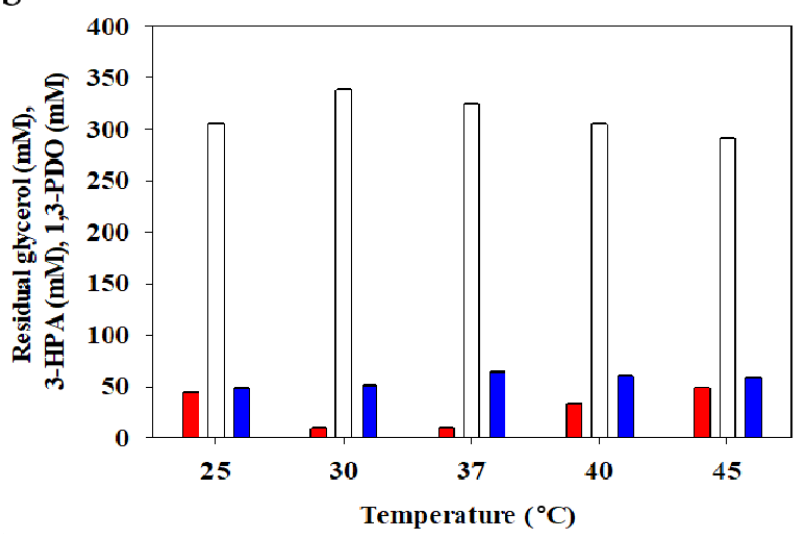

d

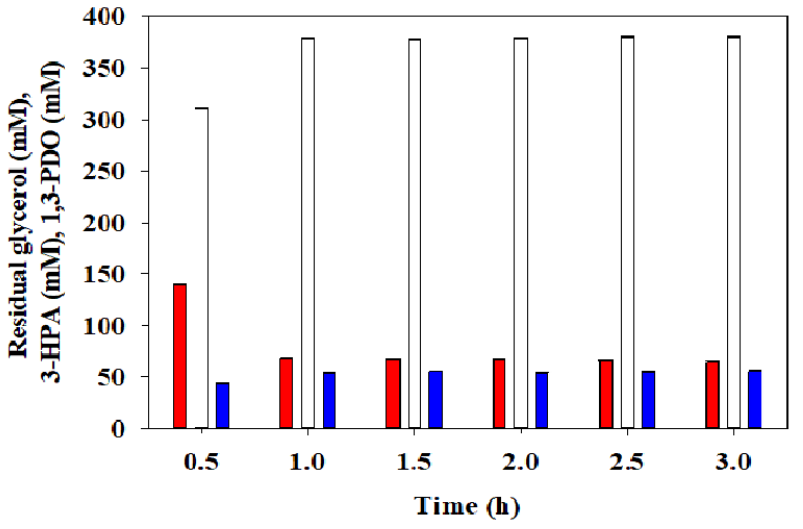

Figure 3. 3-hydroxypropionaldehyde bioconversion at a different cell density (a), bioconversion temperatures (b), glycerol concentrations (c), and bioconversion times (d). Red bars, residual glycerol; white bars, 3-hydroxypropionaldehyde; blue bars, 1,3-propanediol. All results are averages from three independent experiments.

To confirm the effect of temperature on the bioconversion of 3-HPA and 1,3-PDO, we also measured the enzymatic activities of $d h a B$ and $d h a T$ at different temperatures (Figure 4 ). The results indicated the activities of both enzymes were highest at $37^{\circ} \mathrm{C}$. Furthermore, dhaB activity was only $3 \%$ lower at $30^{\circ} \mathrm{C}$, but dhaT activity was approximately $14 \%$ lower at $30{ }^{\circ} \mathrm{C}$. This lower dhaT activity at $30^{\circ} \mathrm{C}$ corresponds to the reduced production of 1,3-PDO at this temperature and corresponds to our measurements of these metabolites (Figure $3 \mathrm{~b}$ ). The effect of temperature on dhaT in L. panis PM1 strain was similar [21], in that the specific activity was greater at $37^{\circ} \mathrm{C}$ than at $30^{\circ} \mathrm{C}$ regardless of $\mathrm{pH}$ [21]. We used a temperature of $30{ }^{\circ} \mathrm{C}$ for subsequent experiments.

\subsection{The Effect of Substrate Concentration}

We next examined the effect of substrate concentration on the bioconversion of 3-HPA (Figure 3c). The results indicated that 3-HPA bioconversion was the highest (378 $\mathrm{mM})$ when the glycerol concentration was $500 \mathrm{mM}$. The consumption of glycerol was also the greatest $(431.8 \mathrm{mM})$ when the glycerol concentration was $500 \mathrm{mM}$, with reduced levels at higher concentrations presumably due to substrate inhibition. Previous studies of different strains of $L$. reuteri reported that a glycerol concentration above $250 \sim 400 \mathrm{mM}$, decreased 3-HPA due to substrate inhibition $[3,7,14]$. However, our results indicated that L. reuteri BR201 had stable enzyme activity even at a glycerol concentration of $500 \mathrm{mM}$. Therefore, L. reuteri BR201 is highly suitable for producing high concentrations of 3-HPA. We used a glycerol concentration of $500 \mathrm{mM}$ for subsequent experiments. 
a

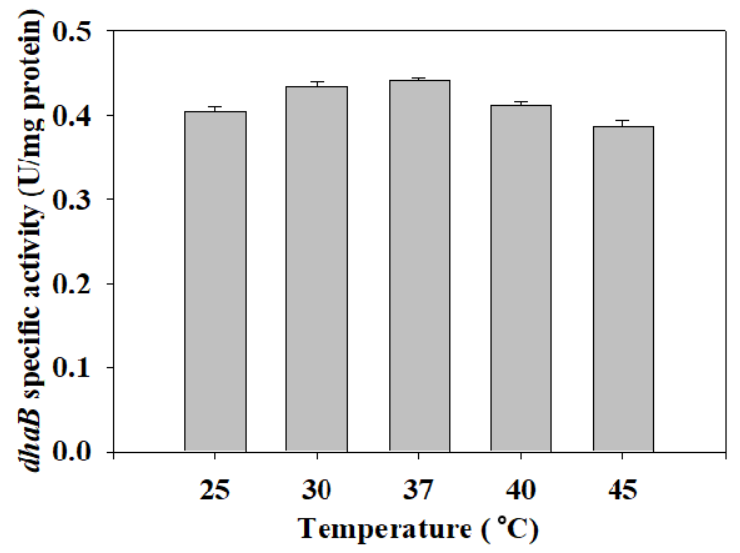

b

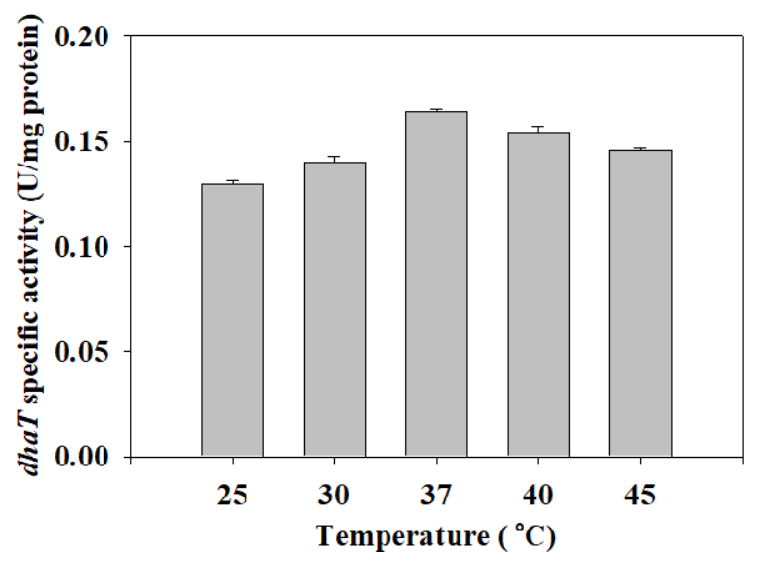

Figure 4. The Effect of temperature on the relative enzyme activity of vitamin $\mathrm{B}_{12}$-dependent glycerol dehydratase, dhaB (a) and 1,3-propanediol oxidoreductase, $\operatorname{dhaT}(\mathbf{b})$. All results are averages from three independent experiments.

\subsection{The Effect of Conversion Time}

We next examined the effect of conversion time on the bioconversion of 3-HPA (Figure 3d). The results indicated that a bioconversion time of $1.0 \mathrm{~h}$ led to the highest bioconversion of 3-HPA (378.4 mM). There was no significant difference in 3-HPA as the bioconversion time increased further. The 3-HPA bioconversion was very rapid, in that about $90 \%$ of this product was produced within $0.5 \mathrm{~h}$. The dhaB enzyme, which converts glycerol to 3-HPA and uses vitamin $B_{12}$ as a cofactor, is eventually inactivated because the cells cannot regenerate coenzyme $\mathrm{B}_{12}$; instead the catalytic cycle is interrupted by the formation of 5'-deoxyadenosine and the catalytically inactive cobalamin [22], and the altered cofactor remains tightly bound to the active site [23]. A dhaB-reactivating factor in Klebsiella reactivates the inactivated enzyme-bound cyanocobalamin in the presence of free vitamin $\mathrm{B}_{12}$, adenosine triphosphate (ATP), and $\mathrm{Mg}^{2+}$ by mediating the exchange of the tightly bound altered cofactor for a free intact cofactor [24]. A previous study also reported reactivation of dhaB by vitamin $\mathrm{B}_{12}$ and $\mathrm{ATP}$ in L. reuteri [25]. In particular, L. reuteri can produce vitamin $B_{12}$ via glucose metabolism [26-28]. However, during the bioconversion of 3-HPA from aqueous glycerol, this species is unable to produce vitamin $B_{12}$ and ATP because it lacks the ability to use glycerol as a carbon source to produce vitamin $B_{12}$ and ATP $[20,27]$. This explains the negligible effect of increasing the bioconversion time (Figure 3d).

There are several previous studies on the bioconversion of 3-HPA using L. reuteri. Although some studies show higher 3-HPA conversion yield than L. rueteri BR201, no group reported production of more than $300 \mathrm{mM}$ 3-HPA from a single batch. To the best of our knowledge, L. reuteri BR201 produced more 3-HPA than any other isolate without the use of additives (Table S1). It will be a good candidate for the industrialization of 3-HPA derived from lactic acid bacteria.

\subsection{Antibacterial Activity and Stability of 3-HPA}

We tested the antibacterial activity of the 3-HPA that was produced under the $378 \mathrm{mM}$ 3-HPA production conditions, using criteria in the United States Pharmacopeia (USP) Chapter 51 (Table 2). The results indicated the minimal inhibitory concentration (MIC) of 3-HPA was 2 3 $\mathrm{mM}$ for the three bacteria, and was $4 \mathrm{mM}$ for two fungi. These results are similar to those of previous studies [29-31]. 
Table 2. The Effect of 3-hydroxypropionaldehyde concentration on antibiotic activity.

\begin{tabular}{ccccccc}
\hline \multirow{2}{*}{ Pathogen } & \multicolumn{6}{c}{ Response * at Different 3-HPA Concentration (mM) } \\
\cline { 2 - 7 } & $\mathbf{0}$ & $\mathbf{1}$ & $\mathbf{2}$ & $\mathbf{3}$ & $\mathbf{4}$ & MIC (mM) \\
\hline E. coli ATCC 8739 & ++ & + & + & - & - & 3 \\
S. aureus ATCC 6538 & ++ & + & - & - & - & 2 \\
P. aeruginosa ATCC 9027 & ++ & + & - & - & - & 2 \\
C. albicans ATCC 10231 & ++ & + & + & + & - & 4 \\
A. niger ATCC 16404 & ++ & + & + & + & - & 4 \\
${ }^{*}++$ : growth; +: inhibition of growth; - : no growth. & & &
\end{tabular}

3-HPA is widely used as a food preservative because of its high antibacterial activity $[18,31,32]$. When using $3-\mathrm{HPA}$ as a food preservative and in other applications, it is essential to consider safety. In particular, 3-HPA undergoes spontaneous dehydration in aqueous solutions into acrolein, a toxic substance [1] Therefore, we measured the effect of temperature and time on the amount of 3-HPA degradation into acrolein using an initial 3-HPA concentration of $4 \mathrm{mM}$ and a pH below 4.0 (Table 3). The initial $4 \mathrm{mM}$ 3-HPA aqueous solution contained $11.6 \mu \mathrm{M}(0.65 \mathrm{mg} / \mathrm{L})$ acrolein. At $4{ }^{\circ} \mathrm{C}$, there was very little production of acrolein after 4 weeks. At $25^{\circ} \mathrm{C}$, there was a small amount of acrolein increasing after 4 weeks, but this increase was not statistically significant. However, at $37^{\circ} \mathrm{C}$ and $50{ }^{\circ} \mathrm{C}$, there was a significant acrolein production by week-2, and this level then remained relatively constant until week-4. Similarly, Engels et al. reported no acrolein production at $\mathrm{pH} 4.0$ and $4{ }^{\circ} \mathrm{C}$, and that the conversion of 3-HPA to acrolein was reversible, with 3-HPA being favored [17].

Table 3. The Effect of temperature and time on the production of acrolein from 3hydroxypropionaldehyde in aqueous solution.

\begin{tabular}{cccccc}
\hline \multirow{2}{*}{$\begin{array}{c}\text { Temperature } \\
\left({ }^{\circ} \mathbf{C}\right)\end{array}$} & 0 Days & 7 Days & 14 Days & 21 Days & 28 Days \\
\cline { 2 - 6 } & & $0.67 \pm 0.04$ & $0.68 \pm 0.05$ & $0.69 \pm 0.04$ & $0.69 \pm 0.03$ \\
4 & & $1.04 \pm 0.11$ & $1.42 \pm 0.08$ & $1.54 \pm 0.06$ & $1.66 \pm 0.12$ \\
25 & $0.65 \pm 0.02$ & $11.36 \pm 0.37$ & $14.43 \pm 0.32$ & $15.82 \pm 0.14$ & $15.96 \pm 0.18$ \\
37 & & $12.77 \pm 0.42$ & $15.19 \pm 0.28$ & $16.54 \pm 0.24$ & $16.58 \pm 0.11$ \\
50 & & & & & \\
\hline
\end{tabular}

3-HPA is an aldol with hydroxyl and aldehyde functional groups. The process of 3-HPA dehydration and conversion to acrolein is an aldol condensation reaction, a reaction that is more rapid at high temperatures [33,34]. This explains our finding of little or no production of acrolein at $4{ }^{\circ} \mathrm{C}$, but significant production at $37^{\circ} \mathrm{C}$ and $50^{\circ} \mathrm{C}$. Therefore, storage of 3-HPA at a concentration where it functions as an antibacterial $(4 \mathrm{mM})$ should be below room temperature to prevent degradation into acrolein.

\section{Material and Methods}

\subsection{Materials and Growth Media}

De Man, Rogosa, and Sharpe (MRS; Difco, Sparks, MD, USA) agar and broth were used for cultivation of L. reuteri; tryptic soy broth (TSB; Difco) was used for cultivation of bacteria; and Sabouraud dextrose broth (SDB; Difco) was used for cultivation of fungi. Acrolein was purchased from Fluka (Buchs, Switzerland); 2,4-dinitrophenylhydrazine (DNPH), acrolein-2,4-DNPH, D,L-tryptophan, bromocresol purple, and sulfuric acid were purchased from Sigma (St. Louis, MO, USA); And HPLC water, acetonitrile, hydrochloric acid, and glycerol were purchased from Daejung Chemicals (Siheung, Korea). All materials were used as received, without pretreatment. 


\subsection{Isolation of L. reuteri Strain}

Lactobacillus reuteri BR201 was isolated from infant feces. First, $1 \mathrm{~g}$ of infant feces samples were serially diluted in $10 \mathrm{~mL}$ of $0.22 \mu \mathrm{m}$ filtered PBS buffer $(\mathrm{pH}$ 6.8). Then, $100 \mu \mathrm{L}$ samples diluted in $10^{5} \sim 10^{7}$ were spread on MRS agar containing $20 \mathrm{~g} / \mathrm{L}$ glycerol and $0.3 \mathrm{~g} / \mathrm{L}$ bromocresol purple. The agar plates were incubated at $37^{\circ} \mathrm{C}$ for $24 \mathrm{~h}$ in an anaerobic chamber (Shellab, Cornelius, OR, USA). The primary isolation was performed by colorimetric method using bromocresol purple. The identification of the Lactobacillus reuteri strains among the primary screening strains were conducted using the MALDI Biotyper system [35].

\subsection{Identification of L. reuteri BR201 by $16 S$ rRNA Analysis}

Genomic DNA of L. reuteri BR201 was extracted using a genomic DNA mini kit (Invitrogen, Waltham, MA, USA). The $16 \mathrm{~S}$ rRNA gene of L. reuteri BR201 was amplified using two universal primers, 27F (5'-AGAGTTTGATCMTGGCTCAG-3') and 1492R (5'-GGTTACCTTGTTACGACTT-3') by PCR. The nucleotide sequence of amplified PCR fragment was confirmed by Solgent (Daejeon, Korea). The result was compared with available 16S rRNA gene sequences on NCBI GenBank and EzTaxon [36]. Phylogenetic analysis was conducted by MEGA6 using the neighbor-joining method [37,38]. The bootstrap value for 1000 replicates was calculated for each branch [39].

\subsection{Cultivation of L. reuteri BR201}

Seed cells for batch cultivation were prepared using $50 \mathrm{~mL}$ conical tube containing $30 \mathrm{~mL}$ MRS broth with $20 \mathrm{~g} / \mathrm{L}$ glycerol. The conical tube was statically incubated at $37^{\circ} \mathrm{C}$ for $12 \mathrm{~h}$, and subsequent cultivation was performed in 5-L fermentor (Kobiotech, Incheon, Korea) at an inoculation concentration of $1 \%(v / v)$. Batch cultivations were conducted in a 5-L fermentor that contained $3 \mathrm{~L}$ MRS broth with $20 \mathrm{~g} / \mathrm{L}$ glycerol. All cultivation experiments were conducted with $100 \mathrm{rpm}$ and without aeration at $37^{\circ} \mathrm{C}$. The $\mathrm{pH}$ was maintained at $5.5 \pm 0.1$ using $6 \mathrm{M} \mathrm{NaOH}$. Cell growth was measured by absorbance at $\mathrm{OD}_{600 \mathrm{~nm}}$. All results are presented as averages from three independent experiments.

\subsection{Cultivation Metabolite Analysis}

The concentrations of residual carbon sources and metabolites were determined using an Agilent 1200 series high-performance liquid chromatography (HPLC) system (Agilent Technologies, Santa Clara, CA, USA) that had an Aminex HPX-87H column $(300 \times 7.8 \mathrm{~mm}$; Bio-Rad, Hercules, CA, USA) and a refractive index detector (RID). As the mobile phase, $2.5 \mathrm{mM} \mathrm{H}_{2} \mathrm{SO}_{4}$ was used, and the flow rate was $0.6 \mathrm{~mL} / \mathrm{min}$. The temperatures of the column oven and the RID cell were $65^{\circ} \mathrm{C}$ and $45^{\circ} \mathrm{C}$, respectively [40].

\subsection{3-HPA Bioconversion}

Cells resulting from $8 \mathrm{~h}$ of cultivation in a $5 \mathrm{~L}$ fermentor were used for 3-HPA bioconversion. The cultivation broth was first centrifuged to obtain resting cells. Then, the resting cells were washed with $1 / 2$ volume DW, resuspended in an aqueous glycerol solution, and transferred to a constant temperature incubator. Unless otherwise noted, the conditions used for of 3-HPA bioconversion were cell density $\mathrm{OD}_{600 \mathrm{~nm}} 100$, glycerol concentration of $400 \mathrm{mM}$, bioconversion temperature of $37^{\circ} \mathrm{C}$, and bioconversion time of $1 \mathrm{~h}$. For 3-HPA bioconversion, the effects of cell density, bioconversion temperature, glycerol concentration, and bioconversion time were then determined. After different experimental treatments, the bioconversion solution was centrifuged to remove the cells and passed through a $0.22 \mu \mathrm{m}$ filter. Quantification of the 3-HPA was determined using the acrolein coloring method [41]. In particular, a $100 \mu \mathrm{L}$ of sample was thoroughly mixed with $75 \mu \mathrm{L}$ of a $10 \mathrm{mM}$ DL-tryptophan solution (dissolved in $0.05 \mathrm{mM} \mathrm{HCl}$ ), and $300 \mu \mathrm{L}$ of $\mathrm{HCl} 37 \%(w / v)$. Mixtures containing samples and standards were incubated for $20 \mathrm{~min}$ in a water bath at $37^{\circ} \mathrm{C}$, and $\mathrm{OD}_{560 \mathrm{~nm}}$ was then measured [14]. The enzymatic activities of dhaB and dhaT were measured as previously described [28]. 


\subsection{Measurement of Antimicrobial Activity}

Five microbes were used for antibacterial activity tests, as described in Chapter 51 of the USP (Antimicrobial Effectiveness Testing). There were threee bacteria (Escherichia coli ATCC 8739, Pseudomonas aeruginosa ATCC 9027, Staphylococcus aureus ATCC 6538), one yeast (Candida albicans ATCC 10231), and one mold (Aspergillus niger ATCC 16404). These experiments were performed after subculturing twice in TSB (bacteria) or SDB (fungi). The minimum inhibitory concentration (MIC) was used as an indication of antimicrobial activity [42], and the concentration of 3-HPA in these tests ranged from 0 to $5 \mathrm{mM}$. For bacteria, $1 \times 10^{7} \mathrm{CFU} / \mathrm{mL}$ were inoculated into TSB medium containing 3-HPA and incubated at $37^{\circ} \mathrm{C}$ for 3 days. For fungi, $1 \times 10^{5} \mathrm{CFU} / \mathrm{mL}$ were inoculated into SDB medium containing 3-HPA and incubated at $30^{\circ} \mathrm{C}$ for 3 days.

\subsection{Acrolein Analysis}

The concentration of acrolein in the 3-HPA solution was analyzed using the modified 2,4-DNPH derivatization method [43-45]. A $20 \mu \mathrm{L}$ sample was added to $100 \mu \mathrm{L}$ of citric acid/sodium citrate buffer (8:2), $400 \mu \mathrm{L}$ of acetonitrile (ACN), $280 \mu \mathrm{L}$ of DW, and $200 \mu \mathrm{L}$ of $10 \mathrm{mM}$ 2,4-DNPH in ACN at $25^{\circ} \mathrm{C}$. This solution was placed on a shaker $(250 \mathrm{rpm})$ and derivatized for $1 \mathrm{~h}$. The derivatization solution was passed through a $0.45 \mu \mathrm{m}$ Teflon filter, and the concentration of acrolein-2,4-DNPH was determined using an Agilent 1200 series HPLC system (Agilent Technologies) that was equipped with a diode array detector and a ZORBAX eclipse plus C18 column $(250 \times 4.6 \mathrm{~mm}, 5 \mu \mathrm{m}$; Agilent Technologies $)$. The mobile phase was a water/acetonitrile mixture $(4: 6, v / v)$, the flow rate was $1.0 \mathrm{~mL} / \mathrm{min}$, the mobile phase was degassed for $1 \mathrm{~h}$ before use, the column temperature was $30^{\circ} \mathrm{C}$, and the diode array detector measured $\mathrm{OD}_{360 \mathrm{~nm}}$ (Figure S1).

\section{Conclusions}

We isolated L. reuteri BR201, an excellent biocatalyst for 3-HPA bioconversion, and determined effect of bioconversion conditions (cell density, temperature, substrate concentration, time) for the bioconversion of 3-HPA without additives. This strain produced $378 \mathrm{mM}$ of 3-HPA under confirmed conditions. Our assessment of the antimicrobial activity of the resulting 3-HPA indicated it was effective against bacteria and fungi at low concentrations $(4 \mathrm{mM})$. Moreover, storage of the resulting 3-HPA aqueous solution at a low temperature led to minimal degradation into acrolein. These results suggest that LAB-derived 3-HPA has potential for use in various industrial applications.

Supplementary Materials: The following are available online at https://www.mdpi.com/article/10 $.3390 /$ catal11101139/s1.

Author Contributions: Conceptualization, J.-H.J.; methodology, S.-G.J. and S.-Y.H.; investigation, J.-H.J. and S.-G.J; resources, S.-Y.H. and M.-S.K.; writing—original draft preparation, J.-H.J., K.M.L. and B.-R.O.; writing-review and editing, J.-H.J., C.-H.K. and B.-R.O.; supervision, C.-H.K.; project administration, M.-S.K., B.-R.O., funding acquisition, K.M.L. and B.-R.O. All authors have read and agreed to the published version of the manuscript.

Funding: This work was supported by the Korea Research Institute of Bioscience and Biotechnology (KRIBB) Research Initiative Program (KGM5482113). This research was financially supported by the Ministry of Trade, Industry and Energy (MOTIE) and Korea Institute for Advancement of Technology (KIAT) through the International Cooperative R\&D program. (Project No. P0014932).

Data Availability Statement: The datasets supporting the conclusions of this article are included within the article.

Conflicts of Interest: The authors declare no conflict of interest. 


\section{References}

1. Vollenweider, S.; Lacroix, C. 3-Hydroxypropionaldehyde: Applications and Perspectives of Biotechnological Production. Appl. Microbiol. Biotechnol. 2004, 64, 16-27. [CrossRef] [PubMed]

2. Bauer, R.; du Toit, M.; Kossmann, J. Influence of Environmental Parameters on Production of the Acrolein Precursor 3Hydroxypropionaldehyde by Lactobacillus reuteri DSMZ 20016 and Its Accumulation by Wine Lactobacilli. Int. J. Food Microbiol. 2010, 137, 28-31. [CrossRef] [PubMed]

3. Lüthi-Peng, Q.; Schärer, S.; Puhan, Z. Production and Stability of 3-Hydroxypropionaldehyde in Lactobacillus reuteri. Appl. Microbiol. Biotechnol. 2002, 60, 73-80. [PubMed]

4. Arqués, J.L.; Fernández, J.; Gaya, P.; Nuñez, M.; Rodríguez, E.; Medina, M. Antimicrobial Activity of Reuterin in Combination with Nisin Against Food-Borne Pathogens. Int. J. Food Microbiol. 2004, 95, 225-229. [CrossRef]

5. Arqués, J.L.; Rodríguez, E.; Nuñez, M.; Medina, M. Inactivation of Gram-Negative Pathogens in Refrigerated Milk by Reuterin in Combination with Nisin or the Lactoperoxidase System. Eur. Food Res. Technol. 2008, 227, 77-82. [CrossRef]

6. Sobolov, M.; Smiley, K.L. Metabolism of Glycerol by an Acrolein-Forming Lactobacillus. J. Bacteriol. 1960, 79, 261-266. [CrossRef]

7. Talarico, T.L.; Casas, I.A.; Chung, T.C.; Dobrogosz, W.J. Production and Isolation of Reuterin, a Growth Inhibitor Produced by Lactobacillus reuteri. Antimicrob. Agents Chemother. 1988, 32, 1854-1858. [CrossRef]

8. Talarico, T.L.; Dobrogosz, W.J. Chemical Characterization of an Antimicrobial Substance Produced by Lactobacillus reuteri. Antimicrob. Agents Chemother. 1989, 33, 674-679. [CrossRef]

9. Hayek, S.A.; Ibrahim, S.A. Current Limitations and Challenges with Lactic Acid Bacteria: A Review. Food Nutr. Sci. $2013,4,40133$. [CrossRef]

10. Kumar, V.; Ashok, S.; Park, S. Recent Advances in Biological Production of 3-Hydroxypropionic Acid. Biotechnol. Adv. 2013, 31, 945-961. [CrossRef]

11. U.S. Food and Drug Administration. Generally Recognized as Safe (GRAS) Determination of Lactobacillus reuteri Strain DSM 17938; FDA: Silver Sping, MD, USA, 2008.

12. Lüthi-Peng, Q.; Dileme, F.; Puhan, Z. Effect of Glucose on Glycerol Bioconversion by Lactobacillus reuteri. Appl. Microbiol. Biotechnol. 2002, 59, 289-296. [PubMed]

13. Vieira, P.B.; Kilikian, B.V.; Bastos, R.V.; Perpetuo, E.A.; Nascimento, C.A.O. Process Strategies for Enhanced Production of 1,3-Propanediol by Lactobacillus reuteri Using Glycerol as a Co-Substrate. Biochem. Eng. J. 2015, 94, 30-38. [CrossRef]

14. Doleyres, Y.; Beck, P.; Vollenweider, S.; Lacroix, C. Production of 3-Hydroxypropionaldehyde Using a Two-Step Process with Lactobacillus reuteri. Appl. Microbiol. Biotechnol. 2005, 68, 467-474. [CrossRef] [PubMed]

15. Stevens, M.J.A.; Vollenweider, S.; Mertes, P.; Lacroix, C. Bisulfite as Scavenger for Enhanced Biotechnological Production of 3-Hydroxypropionaldehyde by Lactobacillus reuteri. Biochem. Eng. J. 2013, 79, 239-245. [CrossRef]

16. Sardari, R.R.R.; Dishisha, T.; Pyo, S.-H.; Hatti-Kaul, R. Semicarbazide-Functionalized Resin as a New Scavenger for In Situ Recovery of 3-Hydroxypropionaldehyde during Biotrans-Formation of Glycerolby Lactobacillus reuteri. J. Biotechnol. 2014, 192, 223-230. [CrossRef] [PubMed]

17. Engels, C.; Schwab, C.; Zhang, J.; Stevens, M.J.A.; Bieri, C.; Ebert, M.-O.; McNeill, K.; Sturla, S.J.; Lacroix, C. Acrolein Contributes Strongly to Antimicrobial and Heterocyclic Amine Transformation Activities of Reuterin. Sci. Rep. 2016, 6, 36246. [CrossRef]

18. Stevens, M.; Vollenweider, S.; Lacroix, C.; Zurich, E.T.H. 5-The Potential of Reuterin Produced by Lactobacillus reuteri as a Broad Spectrum Preservative in Food. In Protective Cultures, Antimicrobial Metabolites and Bacteriophages for Food and Beverage Biopreservation; Lacroix, C., Ed.; Woodhead Publishing: Sawston, UK, 2011; pp. 129-160.

19. Abraham, K.; Andres, S.; Palavinskas, R.; Berg, K.; Appel, K.E.; Lampen, A. Toxicology and Risk Assessment of Acrolein in Food. Mol. Nutr. Food Res. 2011, 55, 1277-1290. [CrossRef]

20. Ju, J.-H.; Heo, S.-Y.; Choi, S.-W.; Kim, Y.-M.; Kim, M.-S.; Kim, C.-H.; Oh, B.-R. Effective Bioconversion of 1,3-Propanediol from Biodiesel-Derived Crude Glycerol Using Organic Acid Resistance-Enhanced Lactobacillus reuteri JH83. Bioresour. Technol. 2021, 337, 125361. [CrossRef]

21. Kang, T.S.; Korber, D.R.; Tanaka, T. Glycerol and Environmental Factors: Effects on 1,3-Propanediol Production and NAD+ Regenerationin Lactobacillus panis PM1. J. Appl. Microbiol. 2013, 115, 1003-1011. [CrossRef]

22. Daniel, R.; Bobik, T.A.; Gottschalk, G. Biochemistry of Coenzyme B12-Dependent Glycerol and Diol Dehydratases and Organization of the Encoding Genes. FEMS Microbiol. Rev. 1998, 22, 553-566. [CrossRef]

23. Mori, K.; Hosokawa, Y.; Yoshinaga, T.; Toraya, T. Diol Dehydratase-Reactivating Factor Is a Reactivase-Evidence for Multiple Turnovers and Subunit Swapping with Diol Dehy-Dratase. FEBS J. 2010, 227, 4931-4943. [CrossRef] [PubMed]

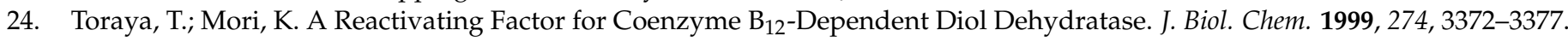
[CrossRef] [PubMed]

25. Liu, F.; Yu, B. Efficient Production of Reuterin from Glycerol by Magnetically Immobilized Lactobacillus reuteri. Appl. Microbiol. Biotechnol. 2015, 99, 4659-4666. [CrossRef] [PubMed]

26. Taranto, M.P.; Vera, J.L.; Hugenholtz, J.; De Valdez, G.F.; Sesma, F. Lactobacillus reuteri CRL1098 Produces Cobalamin. J. Bacteriol. 2003, 185, 5643-5647. [CrossRef]

27. Santos, F.; Teusink, B.; Molenaar, D.; van Heck, M.; Wels, M.; Sieuwerts, S.; de Vos, W.M.; Hugenholtz, J. Effect of Amino Acid Availability on Vitamin $B_{12}$ Production in Lactobacillus reuteri. Appl. Environ. Microbiol. 2009, 75, 3930. [CrossRef] 
28. Ju, J.-H.; Wang, D.; Heo, S.-Y.; Kim, M.-S.; Seo, J.-W.; Kim, Y.-M.; Kim, D.-H.; Kang, S.-A.; Kim, C.-H.; Oh, B.-R. Enhancement of 1, 3-Propanediol Production from Industrial By-Productby Lactobacillus reuteri CH53. Microb. Cell Fact. 2020, 19, 1-10. [CrossRef]

29. Rasch, M. The Influence of Temperature, Salt and $\mathrm{pH}$ on the Inhibitory Effect of Reuterin on Escherichia coli. Int. J. Food Microbiol. 2002, 72, 225-231. [CrossRef]

30. Yunmbam, M.K.; Roberts, J.F. The In Vitro Efficacy of Reuterin on the Culture and Bloodstream Forms of Trypanosoma brucei brucei. Comp. Biochem. Physiol. C Comp. Pharmacol. Toxicol. 1992, 101, 235-238. [CrossRef]

31. Vimont, A.; Fernandez, B.; Ahmed, G.; Fortin, H.-P.; Fliss, I. Quantitative Antifungal Activity of Reuterin Against Food Isolates of Yeasts and Moulds and Its Potential Application in Yogurt. Int. J. Food Microbiol. 2019, 289, 182-188. [CrossRef]

32. El-Ziney, M.G.; van den Tempel, T.; Debevere, J.; Jakobsen, M. Application of Reuterin Produced by Lactobacillus reuteri 12002 for Meat Decontamination and Preservation. J. Food Prot. 1999, 62, 257-261. [CrossRef]

33. Crouch, R.D.; Richardson, A.; Howard, J.L.; Harker, R.L.; Barker, K.H. The Aldol Addition and Condensation: The Effect of Conditions on Reaction Pathway. J. Chem. Educ. 2007, 84, 475. [CrossRef]

34. Josephson, D.B.; Lindsay, R.C. Retro-Aldol Degradations of Unsaturated Aldehydes: Role in the Formation of c4-Heptenal from t2, c6-Nonadienal in Fish, Oyster and Other Flavors. J. Am. Oil Chem. Soc. 1987, 64, 132-138. [CrossRef]

35. Buchan, B.W.; Riebe, K.M.; Ledeboer, N.A. Comparison of the MALDI Biotyper System Using Sepsityper Specimen Processing to Routine Microbiological Methods for Identification of Bacteria from Positive Blood Culture Bottles. J. Clin. Microbiol. 2012, 50, 346-352. [CrossRef]

36. Kim, O.-S.; Cho, Y.-J.; Lee, K.; Yoon, S.-H.; Kim, M.; Na, H.; Park, S.-C.; Jeon, Y.S.; Lee, J.-H.; Yi, H.; et al. Introducing EzTaxon-E: A Prokaryotic 16S rRNA Gene Sequence Database with Phylotypes that Represent Uncultured Species. Int. J. Syst. Evol. Microbiol. 2012, 62, 716-721. [CrossRef] [PubMed]

37. Tamura, K.; Stecher, G.; Peterson, D.; Filipski, A.; Kumar, S. MEGA6: Molecular Evolutionary Genetics Analysis Version 6.0. Mol. Biol. Evol. 2013, 30, 2725-2729. [CrossRef] [PubMed]

38. Saitou, N.; Nei, M. The Neighbor-Joining Method: A New Method for Reconstructing Phylogenetic Trees. Mol. Biol. Evol. 1987, 4, 406-425.

39. Felsenstein, J. Confidence Limits on Phylogenies: An Approach Using the Bootstrap. Evolution 1985, 39, 783-791. [CrossRef]

40. Ju, J.-H.; Ko, D.-J.; Heo, S.-Y.; Lee, J.-J.; Kim, Y.-M.; Lee, B.-S.; Kim, M.-S.; Kim, C.-H.; Seo, J.-W.; Oh, B.-R. Regulation of Lipid Accumulation Using Nitrogen for Microalgae Lipid Production in Schizochytrium sp. ABC101. Renew. Energy 2020, 153, 580-587. [CrossRef]

41. Circle, S.J.; Stone, L.; Boruff, C.S. Acrolein Determination by Means of Tryptophane. A Colorimetric Micromethod. Ind. Eng. Chem. Anal. Ed. 1945, 17, 259-262. [CrossRef]

42. Asare, P.T.; Zurfluh, K.; Greppi, A.; Lynch, D.; Schwab, C.; Stephan, R.; Lacroix, C. Reuterin Demonstrates Potent Antimicrobial Activity Against a Broad Panel of Human and Poultry Meat Campylobacter spp. Isolates. Microorganisms 2020, 8, 78. [CrossRef]

43. Hanoune, B.; LeBris, T.; Allou, L.; Marchand, C.; Le Calve, S.J.A.E. Formaldehyde Measurements in Libraries: Comparison between Infrared Diode Laser Spectroscopy and a DNPH-Derivatization Method. Atmos. Environ. 2006, 40, 5768-5775. [CrossRef]

44. Possanzini, M.; Di Palo, V.; Petricca, M.; Fratarcangeli, R.; Brocco, D.J.A.E. Measurements of Lower Carbonyls in Rome Ambient Air. Atmos. Environ. 1996, 30, 3757-3764. [CrossRef]

45. Slemr, J.; Junkermann, W.; Volz-Thomas, A.J.A.E. Temporal Variations in Formaldehyde, Acetaldehyde and Acetone and Budget of Formaldehyde at a Rural Site in Southern Germany. Atmos. Environ. 1996, 30, 3667-3676. [CrossRef] 